\title{
A Principal Components-Based Clustering Method to Identify Variants Associated with Complex Traits
}

\author{
Mary Helen Black ${ }^{a}$ Richard M. Watanabe ${ }^{a, b}$

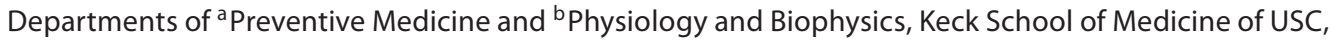 \\ Los Angeles, Calif., USA
}

\section{Key Words}

Complex trait · Genotypes • Principal components •

Cluster analysis

\begin{abstract}
Background: Multivariate methods ranging from joint SNP to principal components analysis (PCA) have been developed for testing multiple markers in a region for association with disease and disease-related traits. However, these methods suffer from low power and/or the inability to identify the subset of markers contributing to evidence for association under various scenarios. Methods: We introduce orthoblique principal components-based clustering (OPCC) as an alternative approach to identify specific subsets of markers showing association with a quantitative outcome of interest. We demonstrate the utility of OPCC using simulation studies and an example from the literature on type 2 diabetes. Results: Compared to traditional methods, OPCC has similar or improved power under various scenarios of linkage disequilibrium structure and genotype availability. Most importantly, our simulations show how OPCC accurately parses large numbers of markers to a subset containing the causal variant or its proxy. Conclusion: OPCC is a powerful and efficient data reduction method for detecting associations between gene variants and disease-related traits. Unlike alternative methodologies, OPCC has the ability to
\end{abstract}

isolate the effect of causal SNP(s) from among large sets of markers in a candidate region. Therefore, OPCC is an improvement over PCA for testing multiple SNP associations with phenotypes of interest.

Copyright ๑ 2011 S. Karger AG, Basel

\section{Introduction}

Candidate gene association studies involve testing genetic variants within a candidate gene or region for association with disease or disease-related traits. Univariate analysis of individual markers in a candidate region requires a multiple testing correction to control the type I error rate, but also results in a loss of power. Joint analysis of all genetic markers allows for inference on an entire region, but warrants subsequent examination of each individual variant for evidence of association. Multivariate methods have been introduced to allow association testing of multiple markers [1-4], but can suffer from low power or inability to effectively condense the examined region to a smaller subset of markers that contains the causal variant(s).

Gauderman et al. [3] introduced a principal components (PC) regression framework to assess whether a candidate region, represented by multiple single nucleotide polymorphisms (SNPs), is associated with disease. PCA 
is used to derive linear transformations of the original SNP data, in which eigenvectors are chosen to maximize the variance of each PC relative to the overall variation in the gene region [3]. The subset of PCs accounting for a substantial proportion of the total variation is analyzed, which reduces the number of parameters to be tested. These PCs are then used as covariates in an omnibus test of association with a trait of interest $[3,4]$.

The PC method has been shown to have greater power to detect association between multiple SNPs and disease than standard joint SNP analyses or haplotype-based tests [3]. However, the coefficients that make up each eigenvector lack specific interpretation. Because the eigenvector elements of a given PC represent the correlation of each SNP with that PC, it has been argued that if a few coefficients are very small and a few are large, the PC represents the SNPs with the largest loadings [5]. However, unless the analysis includes a small number of SNPs, and thus a limited number of PCs, several intermediate loadings typically convolute interpretation of a given PC. Therefore, the specific contribution of each individual SNP to the evidence of association is difficult to assess.

We propose an oblique PC-based clustering (OPCC) method that maintains the favorable attributes of the PC approach, but has the significant advantage of identifying the unique $\mathrm{SNP}(\mathrm{s})$ in the region that contribute to the association signal. The algorithm uses an orthoblique rotation of PCs on a set of genotype data to form disjoint clusters, where each cluster is defined by a specific array of SNPs. The goal is to define a subset of clusters that explains a large proportion of the total locus variation, such that those clusters can then be tested for association with an outcome of interest. We performed simulation studies to compare power and type I error rates between OPCC and alternative analytic approaches under various scenarios. We also use data from the Finland-United States Investigation of NIDDM Genetics (FUSION) study $[6,7]$ to compare these methods in testing for association between tag SNPs in the promoter region of hepatocyte nuclear factor 4- $\alpha$ (HNF4A) and a quantitative trait.

\section{Methods}

\section{Analytic Approaches}

PC-Regression Analysis

Suppose genotype data is collected on $K$ SNPs within a candidate gene region, where $g_{1}, \ldots, g_{K}$ are the genotype scores, each coded as 0,1 , or 2 for observed number of minor alleles. PCA reduces the correlated SNPs to a smaller set of uncorrelated factors representing the genetic variation in the candidate gene region.
Thus, PCs are optimal linear transformations of SNP data, resulting in $K$ orthogonal linear models:

$$
\begin{gathered}
\mathrm{PC}_{1}=\mathbf{e}_{1} \mathbf{g}=e_{11} g_{1}+e_{21} g_{2}+\ldots+e_{k 1} g_{k}, \operatorname{Var}\left(P C_{1}\right)=\lambda_{1} \\
\vdots \\
\mathrm{PC}_{k}=\mathbf{e}_{k} \mathbf{g}=e_{1 k} g_{1}+e_{2 k} g_{2}+\ldots+e_{k k} g_{k}, \operatorname{Var}\left(P C_{k}\right)=\lambda_{k}
\end{gathered}
$$

such that the $k$-th eigenvalue $\left(\lambda_{k}\right)$ corresponds to the $k$-th eigenvector $\left(\mathbf{e}_{k}\right)$, and the $K$ eigenvector elements for each eigenvalue represent the coefficients, or weights, of $K$ SNPs for each linear model. Eigenvectors are determined subject to the constraint that $\mathbf{e}_{k}{ }^{\mathrm{T}} \mathbf{e}_{k}=1$ and $\mathbf{e}_{i}{ }^{\mathrm{T}} \mathbf{e}_{\boldsymbol{k}}=0$, for $i \neq k$, such that the covariance of $\mathrm{PC}_{i}$ with $\mathrm{PC}_{k}$ is equal to 0 , for $i \neq j$. Thus, $\mathrm{PC}_{1}$ is uncorrelated with any other PC, and represents the linear combination of SNPs that explains the most genetic variation in the region. Similarly, $\mathrm{PC}_{2}$ is uncorrelated with any $\mathrm{PC}$, and explains the next largest amount of SNP variation, and so forth $\left(\lambda_{1}>\lambda_{2}>\ldots>\lambda_{k}\right)$. Given:

$$
\sum_{k=1}^{K} \operatorname{Var}\left(g_{k}\right)=\sum_{k=1}^{K} \operatorname{Var}\left(P C_{k}\right)=\lambda_{1}+\lambda_{2}+\ldots+\lambda_{k}
$$

the proportion of the overall variation each PC can explain may be written as

$$
\lambda_{k} / \sum_{k=1}^{K} \lambda_{k}
$$

If a set of $K$ variables (where $K>2$ ) have substantial correlation among them, then the first few PCs should account for most of the variation in the original variables [5]. Thus, only a subset $S$ of PCs $\left(\mathrm{PC}_{1}, \mathrm{PC}_{2}, \ldots, \mathrm{PC}_{S}, S<K\right)$ explaining a large proportion of the total genetic variation need to be tested for association in a regression framework $[3,4]$ :

$$
y=\beta_{0}+\sum_{s=1}^{S} \beta_{s} P C_{s}
$$

An S-d.f. likelihood ratio test (LRT) of model (4) versus $y=\beta_{0}$ provides an omnibus test of whether the region, as defined by the subset $S$ of PCs, explains a significant proportion of the variation in trait $y$.

\section{Oblique PC-Based Clustering}

OPCC exploits the use of rotational methods in making the eigenvector loadings on individual PCs more interpretable. The algorithm begins with the $K$ SNPs initially grouped into a single cluster. PCA is performed on the initial cluster, with a quartimaxbased orthoblique rotation [8] applied to the first two PCs $\left(\mathrm{PC}_{1}\right.$, $\mathrm{PC}_{2}$ ), such that each SNP will have a non-zero loading on only one of the two PCs, and a loading of zero on the other. The algorithm assigns each SNP to the rotated component with which it has the higher squared correlation, dividing the initial cluster into two disjoint clusters. PC analysis within newly formed clusters and SNP assignment continue iteratively, assigning SNPs to clusters, and then re-testing each SNP to determine if assigning it to a different cluster increases the amount of variance explained, with the goal of maximizing the total variance accounted for by the cluster components. For $K$ SNPs, we compute $N$ clusters:

$$
\begin{gathered}
\mathrm{C}_{1}=\mathbf{c}_{1} \mathbf{g}=c_{11} g_{1}+c_{21} g_{2}+\ldots+c_{k 1} g_{k} \\
\vdots \\
\mathrm{C}_{n}=\mathbf{c}_{n} \mathbf{g}=c_{1 n} g_{1}+c_{2 n} g_{2}+\ldots+c_{k n} g_{k}
\end{gathered}
$$


Fig. 1. LD structure among the 144 SNPs in the simulated TCF7L2 from a single simulated data set. a LD represented by pair-wise $\mathrm{r}^{2}$. b LD as a function of $\mathrm{D}^{\prime}$. Color key denotes $\mathrm{LD}$, as either $\mathrm{r}^{2}$ or $\mathrm{D}^{\prime}$, ranging from $0-1$.

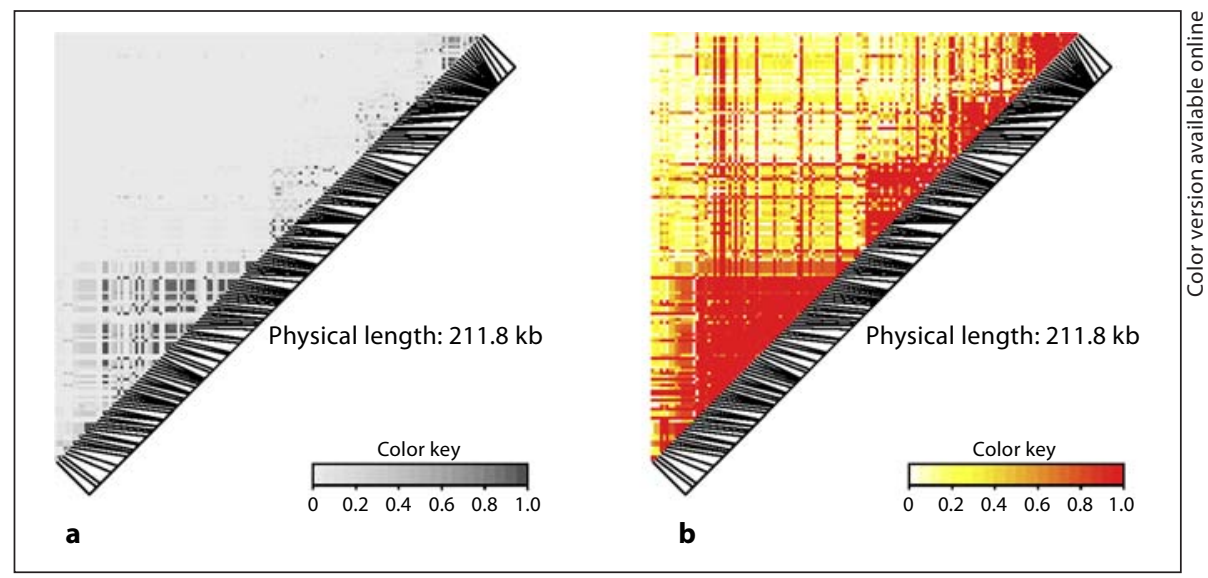

where $\mathrm{C}_{n}$ is the $n$-th cluster score, $\mathbf{c}_{n}$ is a vector of standardized cluster coefficients which are derived from the transformed eigenvector elements, and $\mathbf{g}$ is the vector of SNPs $\left[g_{1}, g_{2}, \ldots, g_{k}\right]$. While all SNPs are subdivided into a total of $N$ clusters, the number of SNPs within each cluster can vary, yielding cluster coefficients equal to zero for SNPs not included in the $n$-th cluster. Given cluster coefficients and genotype scores, cluster scores are computed for each individual. As such, the correlation described above between SNPs and their clusters is determined by alternating least squares for a given SNP regressed on its cluster score:

$$
R^{2}=\frac{S S_{\text {Re } g}}{S S_{\text {Total }}}=\frac{\beta_{g}^{2} \sum_{i}\left(g_{k_{i}}-\bar{g}_{k_{i}}\right)^{2}}{\sum_{i}\left(C_{n_{i}}-\bar{C}_{n_{i}}\right)^{2}}
$$

where $\beta_{\mathrm{SNP}}$ is based on the analysis of variance for regression of the $n$-th cluster versus the $k$-th SNP, $\bar{g}_{k}$ is the mean value for the $k$-th SNP, which is coded as 0,1 , or 2 according to the number of minor alleles, $\bar{C}_{n_{i}}$ is the mean cluster score for the $n$-th cluster, and $i$ is the number of observations.

As with PCA, $N$ clusters that account for a large proportion of SNP variation may be tested for association with outcomes of interest using a standard regression framework:

$$
y=\beta_{0}+\sum_{n=1}^{N} \beta_{n} C_{n}
$$

While an $N$-d.f. LRT of model (7) versus $y=\beta_{0}$ can be performed as an omnibus test of the gene region, it is reasonable to test clusters individually given the interpretability of each of the $N$ clusters. This can be achieved with either a 1-d.f. LRT for $y=\beta_{0}+\beta_{i} C_{i}$ versus $y=\beta_{0}$, where $i=1, \ldots, N$, or an asymptotically equivalent Wald $\chi_{1}^{2}$ statistic on the parameter estimate $\beta_{i}$, with a modest multiple testing correction applied to the $\mathrm{p}$ values resulting from $N$ tests.

\section{Generation of Genotype Data}

We simulated genotype data modeled on two genes known to be associated with type 2 diabetes mellitus (T2DM) and T2DMrelated traits: transcription factor 7-like 2 (TCF7L2) [9-11] and glucokinase (GCK) [12-14]. These two loci represented different scenarios of gene size, availability of SNP information, and un- derlying patterns of linkage disequilibrium (LD). We used the observed distribution of 144 SNPs in TCF7L2 and 53 SNPs in GCK, from 60 CEU founders in HapMap [15] and the method of Gauderman et al. [3] to simulate SNP genotype data for each gene. The Gauderman approach begins by generating genotypes for a given SNP from a multinomial distribution, with proportions taken from the observed distribution for that SNP in the HapMap data. Additional SNPs are then sampled from their observed distribution, conditional on the previous SNP(s). Given the large number of SNPs and thus the high dimensionality of the sampling space, 15-SNP and 10-SNP fixed window sizes were used to model SNP data for TCF7L2 and GCK, respectively, due to differences in gene size.

The distribution of the simulated genotype data for 144 SNPs in TCF7L2 and 53 SNPs in GCK are shown in figure 1 and online supplementary figure 1 (for all online supplementary material see www.karger.com/doi/10.1159/000323567), respectively. SNPs with minor allele frequencies (MAFs) $<0.01$ were excluded from further analysis. Tag SNPs were identified using Tagger [16], as implemented in Haploview (v. 4.1) [17], with an $\mathrm{r}^{2}$ threshold equal to 0.6 which was chosen in order to simulate SNPs that would be in a wide range of $\mathrm{LD}$ with the putative causal variants (CVs). The pair-wise $\mathrm{r}^{2}$ distribution (cf. online suppl. fig. 2) and haplotype frequencies observed in the simulated data were similar to that observed in HapMap CEU data.

Generation of Quantitative Trait Data

One SNP (not a tag SNP) was chosen to be a CV that was assumed to underlie variation in a continuous phenotype with a coefficient of variation of $40 \%$. For each CV, the continuous trait was simulated as:

$$
y=\alpha+\beta(C V)+\varepsilon ; \text { where } \beta=\sqrt{\frac{\operatorname{Var}(y) \cdot R_{C V}^{2}}{\operatorname{Var}(C V)}}
$$

Here, $R_{C V}^{2}$ is the proportion of trait variation accounted for by the $\mathrm{CV}$, and $\operatorname{Var}(\mathrm{CV})$ is calculated according to the variance of a multinomial distribution where the minor allele was assumed to have an additive effect on the simulated trait. The residual error $(\varepsilon)$ is sampled from a normal distribution where:

$$
\operatorname{Var}(\varepsilon)=\operatorname{Var}(y)-\beta^{2} \operatorname{Var}(C V)
$$


Table 1. Descriptive statistics for SNPs used as causal loci in the simulated TCF7L2

\begin{tabular}{|c|c|c|c|c|c|c|c|}
\hline \multirow[t]{2}{*}{$\mathrm{CV}$} & \multirow[t]{2}{*}{ Position $^{\mathrm{a}}$} & \multirow[t]{2}{*}{ Location } & \multicolumn{3}{|c|}{ HapMap CEPH data } & \multicolumn{2}{|c|}{ Simulated data } \\
\hline & & & MAF & tag SNP & $\begin{array}{l}\text { Pairwise } \\
\mathrm{r}^{2} \text { between } \\
\text { tag SNP } \\
\text { and CV }\end{array}$ & $\begin{array}{l}\text { Average } \\
\text { minor } \\
\text { allele } \\
\text { frequency }\end{array}$ & $\begin{array}{l}\text { Average } \\
\text { pairwise } \mathrm{r}^{2} \\
\text { between tag } \\
\text { SNP and } \mathrm{CV}^{\mathrm{b}}\end{array}$ \\
\hline SNP 54 & 114793297 & block 5 & 0.051 & SNP 42 & 0.997 & 0.050 & 0.997 \\
\hline SNP 26 & 114748339 & block 5 & 0.250 & SNP 23 & 0.916 & 0.250 & 0.915 \\
\hline SNP 60 & 114777716 & block 5 & 0.417 & SNP 43 & 0.932 & 0.417 & 0.931 \\
\hline SNP 135 & 114843626 & block 12 & 0.167 & SNP 136 & 0.799 & 0.167 & 0.798 \\
\hline SNP 143 & 114847519 & block 12 & 0.242 & SNP 136 & 0.784 & 0.242 & 0.784 \\
\hline SNP 141 & 114844373 & block 12 & 0.416 & SNP 138 & 0.781 & 0.417 & 0.781 \\
\hline SNP 72 & 114788976 & outside & 0.042 & SNP 70 & 0.699 & 0.042 & 0.699 \\
\hline SNP 105 & 114837133 & outside & 0.150 & SNP 102 & 0.748 & 0.151 & 0.747 \\
\hline SNP 94 & 114811797 & outside & 0.333 & SNP 100 & 0.667 & 0.333 & 0.666 \\
\hline
\end{tabular}

a Based on HapMap data release 23a (phase II), NCBI build 36, dbSNP build 126.

b Average across 1,000 simulated genotype data sets.

For all simulations we assumed the $\mathrm{CV}$ to account for $1 \%$ of the total trait variation $\left(R_{C V}^{2}=0.01\right)$. Under these conditions and assuming $\alpha=0.05$, a direct two-sided test of association has approximately $89 \%$ power to detect association between $\mathrm{CV}$ and phenotype in 1,000 subjects.

We independently considered nine CVs for the simulated TCF7L2 and three CVs for the simulated GCK. We varied MAFs, location within the simulated region, and degree of LD with a designated tag SNP. CVs were located within large or small blocks of LD, or in regions between LD blocks. Characteristics of the CVs for TCF7L2 are summarized in table 1, and those for GCK in online supplementary table 1.

One thousand null data sets $(\beta=0)$ and $1,000 \mathrm{CV}$-associated data sets were simulated for each CV and analyzed under two scenarios of genotype availability: (1) tag SNPs only and (2) tag SNPs $+\mathrm{CV}$. We compared PCA and OPCC to traditional joint SNP and single SNP approaches, with data simulated under both scenarios for CVs in TCF7L2. We repeated these analyses using data simulated for CVs in GCK in order to evaluate the performance of PCA and OPCC for candidate genes with differing characteristics. Results for the simulated GCK data were similar to those obtained with the simulated TCF7L2 data and are independently summarized in the supplementary material. The numbers of PCs or clusters to be analyzed were determined by applying both a 60 - and $80 \%$ explained variance threshold for PCA and OPCC, respectively.

Multi-d.f. tests were evaluated with an LRT for the full model (multiple SNPs, PCs or clusters) versus a null model (intercept only). Single-d.f. tests were evaluated with a Wald $\chi_{1}^{2}$ statistic and p values corrected for multiple testing with Bonferroni. Estimated type I error and power were assessed as the proportion of null and $\mathrm{CV}$-associated data sets, respectively, that yielded a significant association assuming a two-sided alternative hypothesis and a 0.05 significance level.

PC-Based Clustering Approach to Association Analysis

\section{Data Analysis}

HNF4A is one of several candidate genes investigated by the FUSION study which showed association with T2DM $[7,18]$ and T2DM-related traits [7]. Our aim was to replicate the association between HNF4A rs2144908 and 2-hour insulin levels, in 216 unaffected spouses from the FUSION study [7] as a practical demonstration of the OPCC approach. For this comparison, we applied OPCC, PCA, and joint SNP analysis to 11 tag SNPs spanning $\sim 49.2 \mathrm{~kb}$ in the $\mathrm{P} 1$ and $\mathrm{P} 2$ promoter regions of $H N F 4 A$.

\section{Results}

\section{Simulation Studies}

Type 1 error rates for the OPCC approach were within $5 \%$ for all simulation conditions tested (cf. online suppl. table 2) and were consistently within 5\% for all methods tested, although there was a tendency for PCA and OPCC to have marginally better type I error rates compared to single or joint SNP analyses.

We summarize results for the simulated TCF7L2 under the two scenarios of genotype availability. An average of 10.9 PCs and 15.5 clusters were necessary to explain $60 \%$ of the overall locus variation under scenario 1 (54 tags only). This increased to an average of 19.1 PCs and 27.9 clusters when the $80 \%$ explained variance threshold was applied to the same data. Similar numbers of PCs and clusters were required when examining scenario 2 (54 tags $+\mathrm{CV}$ ), with the same increase in the number of PCs 


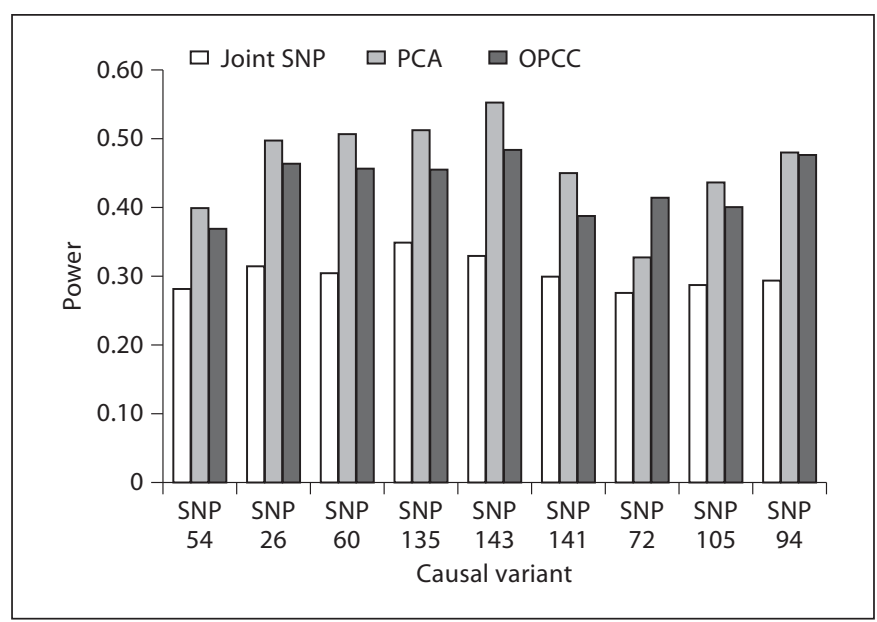

Fig. 2. Estimated power for global association. Estimated power for the global test of association for PC and OPCC are shown for scenario 2 of genotype availability (54 tags $+\mathrm{CV}$ ) and the different CVs in the simulated TCF7L2 (see text for details). White bar denotes joint SNP analysis. Light and dark grey bars denote PCA for number of PCs, and OPCC for number of clusters, explaining $60 \%$ of SNP variation, respectively.

or clusters required to explain the higher proportion of variance.

Both PCA and OPCC approaches had better power than joint SNP analysis in an omnibus test of association, under both scenarios 1 and 2 (fig. 2). The OPCC global association test showed similar power to global PCA under both scenarios, whether a 60 - or an $80 \%$ explained variance threshold was applied. Interestingly, analyses involving the number of PCs or clusters explaining only $60 \%$ of the total locus variation retained more power to detect omnibus association than those meeting the $80 \%$ explained variance threshold, which is partly due to the increased degrees of freedom required to explain the larger amount of variance for the latter.

If individual PCs or clusters are tested, OPCC generally performs as well as or better than the single SNP test or PCA even after correction for multiple testing (fig. 3). When 54 tags and the CV were genotyped (scenario 2), OPCC had approximately 3-28\% greater power than PCA for all tests (fig. 3). The largest improvement in power (15-28\% increase) was observed for univariate tests of clusters where CVs were in the lowest ranges of LD with their designated tags $\left(\mathrm{r}^{2}: 0.66-0.75\right)$ and located outside any LD block. Similar increases in power $(14-17 \%$ increase) were observed for univariate tests of clusters versus PCs where CVs were of low to moderate frequency

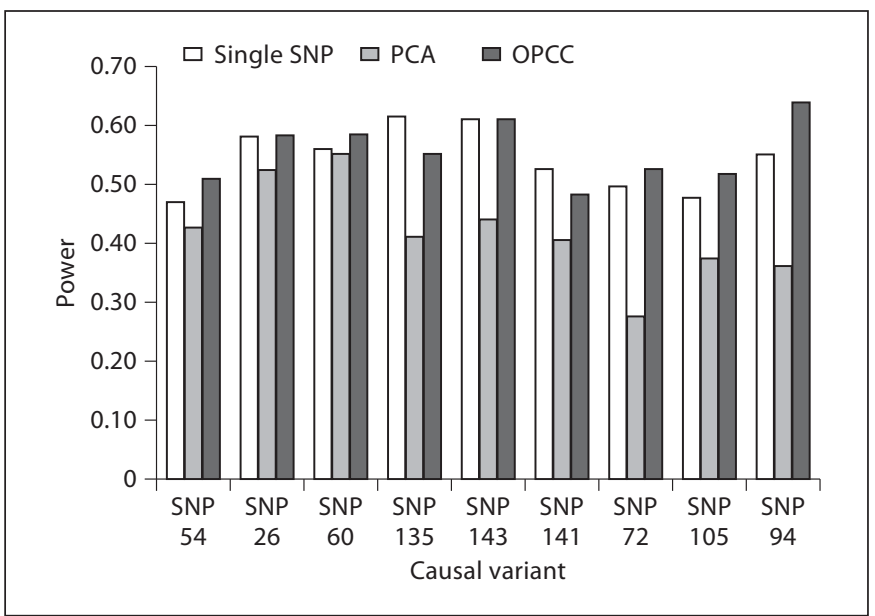

Fig. 3. Estimated power for univariate test of association. Estimated power for the univariate test of association for PC and OPCC are shown for scenario 2 of genotype availability (54 tags $+\mathrm{CV}$ ) and the different CVs in the simulated TCF7L2 (see text for details). White bar denotes single SNP analysis. Light and dark grey bars denote PCA for number of PCs, and OPCC for number of clusters, explaining $60 \%$ of SNP variation, respectively.

(MAFs 16-24\%) and in modest LD with designated tags $\left(r^{2}: 0.78-0.80\right)$. Moreover, tests of individual PCs were substantially less powerful under the $80 \%$ explained variance threshold compared to the $60 \%$ threshold, for all CVs tested, while power for OPCC was similar under either threshold (cf. online suppl. fig. 3 and 4).

We next assessed the ability of the OPCC approach to identify clusters containing the $\mathrm{CV}$ or a tag SNP in strong $\mathrm{LD}$ with the $\mathrm{CV}$ by determining the proportion of correct identifications out of the number of associations detected (table 2). OPCC accuracy was similar to the single SNP test when the $\mathrm{CV}$ was not genotyped, in which significant association with the appropriate tag was considered a correct identification (80 vs. $79 \%$, cf. table 2). However, when the CV was genotyped, OPCC identified clusters containing the true $\mathrm{CV}$ associated with the outcome, an average $91 \%$ of the time, outperforming single SNP tests which identified the correct CV only $86 \%$ of the time. This estimation could not be performed for the PC analysis, due to the uninterpretable nature of the numerous eigenvector loadings on individual PCs.

\section{Data Analysis}

We applied OPCC to replicate the association between HNF4A rs2144908 and 2-hour insulin in unaffected spouses from the FUSION study [7]. The joint SNP anal- 
Table 2. Proportion ${ }^{\mathrm{a}}$ of CVs (or tag SNPs) in the simulated TCF7L2 correctly identified by the OPCC method

\begin{tabular}{|c|c|c|}
\hline Available data & $\begin{array}{l}\text { Single } \\
\text { SNPb }^{b}\end{array}$ & $\mathrm{OPCC}^{\mathrm{c}}$ \\
\hline \multicolumn{3}{|l|}{ Scenario 1: tag SNPs only } \\
\hline SNP 54 (rare, block 5) & 0.857 & 0.788 \\
\hline SNP 26 (moderate, block 5) & 0.876 & 0.815 \\
\hline SNP 60 (common, block 5) & 0.817 & 0.883 \\
\hline SNP 135 (low, block 12) & 0.838 & 0.861 \\
\hline SNP 143 (moderate, block 12) & 0.838 & 0.815 \\
\hline SNP 141 (common, block 12) & 0.734 & 0.768 \\
\hline SNP 72 (rare, outside block) & 0.752 & 0.884 \\
\hline SNP 105 (moderate, outside block) & 0.669 & 0.717 \\
\hline SNP 94 (common, outside block) & 0.706 & 0.704 \\
\hline \multicolumn{3}{|l|}{ Scenario 2: tag SNPs + CV } \\
\hline SNP 54 (rare, block 5) & 0.859 & 0.892 \\
\hline SNP 26 (moderate, block 5) & 0.872 & 0.910 \\
\hline SNP 60 (common, block 5) & 0.834 & 0.923 \\
\hline SNP 135 (low, block 12) & 0.886 & 0.927 \\
\hline SNP 143 (moderate, block 12) & 0.888 & 0.954 \\
\hline SNP 141 (common, block 12) & 0.817 & 0.869 \\
\hline SNP 72 (rare, outside block) & 0.877 & 0.951 \\
\hline SNP 105 (moderate, outside block) & 0.821 & 0.932 \\
\hline SNP 94 (common, outside block) & 0.882 & 0.914 \\
\hline \multicolumn{3}{|c|}{$\begin{array}{l}\text { a Proportion of association results from analysis on } 1,000 \mathrm{CV}- \\
\text { ssociated data sets for each CV that correctly identify the CV } \\
\text { scenario 1) or its tag SNP (scenario } 2 \text { ). } \\
\text { b Single SNP test of association, } 1 \text { d.f., Bonferroni-corrected. } \\
\text { c OPCC univariate test of association, } 1 \text { d.f., Bonferroni-cor- } \\
\text { ected. Assumes } 60 \% \text { explained-variance threshold. }\end{array}$} \\
\hline
\end{tabular}

ysis showed trend for association with 2-hour insulin levels $(\mathrm{p}=0.098)$. PC analysis yielded 3 PCs that accounted for at least $60 \%$ of the variance and were marginally associated with 2 -hour insulin in a joint model $(\mathrm{p}=0.067)$. The eigenvector coefficients ranged from -0.433 to 0.632 ; due to the large number of intermediate loadings, no obvious pattern emerged among the coefficients that suggested which SNPs load onto which PCs. Thus, PCA allows us to conclude that the promoter region of HNF4A shows trend for association with 2-hour insulin, but does not permit us to distinguish the relative contribution of each of the 11 SNPs to this association.

Our OPCC approach identified 3 clusters that accounted for at least $60 \%$ of the variance, with cluster sizes ranging from 3 to 4 SNPs. The 3 SNP-clusters were jointly associated with 2-hour insulin $(p=0.039)$. SNP assignment and Bonferroni-corrected $\mathrm{p}$-values from Wald $\chi^{2}$ tests for univariate association between each cluster and 2-hour insulin are shown in table 3. The squared correlation coefficients between each SNP and its assigned cluster $\left(\mathrm{R}_{\mathrm{O}}^{2}\right)$, indicate that most SNPs within each cluster share a high degree of correlation, and relatively low correlation with SNPs in any other cluster $\left(\mathrm{R}_{\mathrm{N}}^{2}\right)$. Additionally, low values for the ratio of one minus each of these correlations, $\left(1-\mathrm{R}_{\mathrm{O}}^{2}\right) /\left(1-\mathrm{R}_{\mathrm{N}}^{2}\right)$, indicate well-separated clusters. Cluster 3 was significantly associated with 2-hour insulin (Bonferroni $\mathrm{p}=0.033$ ) and contained rs2144908, the SNP showing evidence for association with 2-hour insulin levels in the original FUSION

Table 3. HNF4A SNP-cluster associations with 2-h OGTT insulin in FUSION data

\begin{tabular}{|c|c|c|c|c|c|c|c|}
\hline Cluster No. & SNP & Position $^{\dagger}$ & MAF & $\mathrm{R}_{\mathrm{O}}^{2 \ddagger}$ & $\mathrm{R}_{\mathrm{N}}^{2 \wedge}$ & $\begin{array}{l}\left(1-\mathrm{R}_{\mathrm{O}}^{2}\right) /\left(1-\mathrm{R}_{\mathrm{N}}^{2}\right) \\
\text { ratio }\end{array}$ & p value \\
\hline \multirow[t]{4}{*}{1} & rs6073425 & 42447340 & 0.325 & 0.432 & 0.013 & 0.575 & 1.0 \\
\hline & rs2425637 & 42457463 & 0.496 & 0.730 & 0.105 & 0.302 & \\
\hline & rs2425638 & 42460043 & 0.186 & 0.558 & 0.012 & 0.446 & \\
\hline & rs2425640 & 42461451 & 0.369 & 0.796 & 0.056 & 0.216 & \\
\hline \multirow[t]{4}{*}{2} & rs6031552 & 42412208 & 0.255 & 0.772 & 0.005 & 0.229 & 0.522 \\
\hline & rs11508795 & 42416627 & 0.115 & 0.506 & 0.078 & 0.536 & \\
\hline & rs6031558 & 42433057 & 0.335 & 0.673 & 0.079 & 0.356 & \\
\hline & rs6073418 & 42434004 & 0.287 & 0.337 & 0.130 & 0.762 & \\
\hline \multirow[t]{3}{*}{3} & rs6031544 & 42415761 & 0.296 & 0.766 & 0.189 & 0.289 & 0.033 \\
\hline & rs2144908 & 42419131 & 0.175 & 0.737 & 0.019 & 0.268 & \\
\hline & rs4812831 & 42451674 & 0.120 & 0.501 & 0.060 & 0.531 & \\
\hline
\end{tabular}

\footnotetext{
${ }^{\dagger}$ Based on HapMap data release 23a (phase II), NCBI build 36, dbSNP build 126. ${ }^{\ddagger}$ Squared correlation coefficient between a given SNP and its own cluster. ${ }^{\wedge}$ The next highest squared correlation coefficient between a given SNP and any other cluster. ${ }^{\S} \mathrm{p}$ value from 1 d.f. Wald $\chi^{2}$ for association with outcome, corrected for multiple testing with Bonferroni for number of clusters $(\mathrm{n}=3$ ).
} 
analysis. Moreover, cluster 3 remains significantly associated with 2-hour insulin even after adjustment for all SNP-clusters in the multivariate model $(\mathrm{p}=0.012)$.

\section{Discussion}

The ideal method for testing genetic associations should efficiently identify the SNP(s) that have functional consequences or are in strong LD with the functional variant(s). Many approaches that are currently available only allow for assessing whether a given region may be worthy of additional analysis (e.g. joint SNP analysis and PCA) or are not robust in terms of power (e.g. single SNP analysis). Our simulation study demonstrates that the OPCC method is a powerful alternative to identify associations between the signals in candidate gene regions and quantitative phenotypes. In general, OPCC outperformed PCA over a wide range of conditions, and was most powerful when individual PCs or clusters were tested, despite the use of the overly conservative Bonferroni correction for multiple testing. More importantly, OPCC allows for accurate parsing of a large number of SNPs to a smaller number containing either the functional variant or makers in strong LD with the functional variant. For example, when applied to FUSION data, the OPCC method identified the cluster of SNPs containing the variant previously reported to be associated with OGTT (oral glucose tolerance test) 2-hour insulin.

The orthoblique rotational method implemented in OPCC affords two specific advantages. First, it maintains the power of the traditional PCA approach, while adding a level of interpretability over alternative methodologies. Because eigenvector elements of a given PC can be thought of as the correlation of each SNP with that PC, it has been argued that if the eigenvector coefficients are distributed such that a few are very small and a few are large, the PC can be interpreted as a representation of those variables which show large eigenvector values [5]. However, unless the analysis includes only a small number of SNPs, and hence a small number of PCs, this is usually not the case. Typically, several intermediate loadings convolute interpretation of a given PC. This led to the development of sparse PCA, a modified PCA approach, which considers each PC as a regression-optimization problem; PCA is first applied to the data, and the resulting PCs are regressed on the original variables to recover the loadings while applying a LASSO (least absolute shrinkage and selection operator) penalty to shrink the coefficients toward zero. While this ultimately results in several zero loadings on each of the derived PCs, it does not allow the assignment of each variable to distinct components [19]. In the OPCC approach, the information captured by the eigenvectors of PCA is used to identify SNP clusters, which can then be directly tested for association with phenotypes of interest. Therefore, this particular advantage of OPCC is maximized when sizeable genomic regions containing large numbers of SNPs are examined. Second, our simulation results indicate that OPCC is able to accurately detect the cluster containing the $\mathrm{CV}$, if genotyped, or tag SNPs in strong $\mathrm{LD}$ with the $\mathrm{CV}$ when the $\mathrm{CV}$ is not genotyped. This feature of OPCC was maintained across a wide range of simulation conditions (cf. online suppl. materials) indicating that the method should perform well in real data analysis, as it did when applied to FUSION data.

Additionally, the clustering of SNPs is not predicated on haplotype or block structure. The OPCC approach is not formally based on pair-wise LD, although the correlation among SNPs will likely result in clusters that reflect the LD underlying the region. However, unlike tag SNPs or other methods formally based on LD, OPCC considers the full range of correlation among all SNPs in the region of interest. In fact, in analyses which included all SNPs residing in a given simulated gene (cf. Supplemental Methods), not just those chosen as tags, the OPCC approach had $11-34 \%$ greater power to detect the cluster containing the $\mathrm{CV}$ than analyses of tag SNPs alone, for most CVs tested using either threshold of explained variance (cf. online suppl. fig. 5 and 6). Because of its ability to leverage the correlation among all SNPs in SNP-cluster assignment, the power of the OPCC method is actually enhanced by the inclusion of highly correlated SNPs. Weak correlations and correlation spanning long distances will also be captured by OPCC. The latter is important, given the evidence for functionally-relevant variation in regulatory elements that are distant from the coding region of genes [20,21].

In conclusion, OPCC is a powerful and efficient data reduction method that can be used to detect associations between variation in candidate gene regions and outcomes of interest. Unlike alternative methodologies, OPCC has the ability to isolate the effect of causal SNP(s) from among large sets of variants in a candidate region. Therefore, OPCC is an improvement over PCA for testing multiple variant associations with phenotypes of interest.

\section{Acknowledgements}

The authors thank the FUSION investigators for access to and permission to use their data for this paper. This work was supported by NIH grant (DK-069922) awarded to R.M.W. 


\section{Appendix}

The following example shows the SAS programming code for the OPCC approach proposed in this report. The data matrix includes an individual ID, a normally distributed quantitative trait, and several SNPs, each coded as 0,1 , or 2 according to the number of minor alleles that comprise a given individual's genotype. The
VARCLUS procedure takes SNP data as input and outputs SNPcluster correlations and cluster component scores, by number of clusters. This example assumes 3 clusters are required to achieve the desired threshold of explained locus variance. The score procedure computes cluster scores from individual genotype scores and cluster components. Cluster scores can then be tested for association in a regression framework.

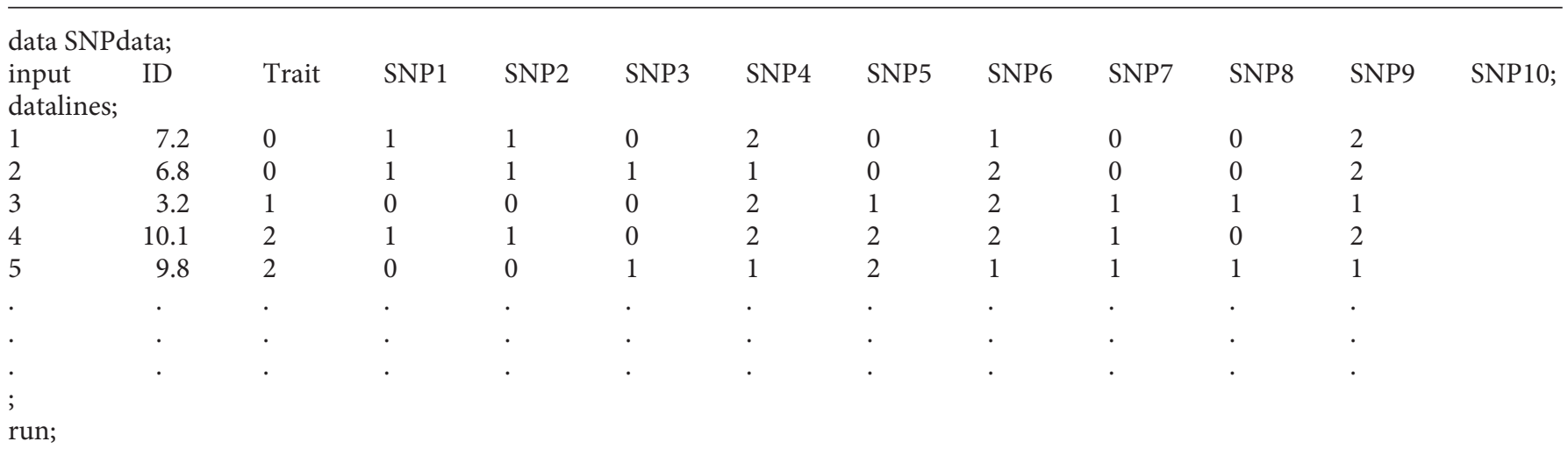

proc varclus data $=$ SNPdata outstat $=$ ClusterOut maxclusters $=3$; var SNP1 SNP2 SNP3 SNP4 SNP5 SNP6 SNP7 SNP8 SNP9 SNP10; run;

data MakeScore;

set ClusterOut;

where $\_\mathrm{NCL}_{-}=3$ or $\_\mathrm{NCL}_{-}=$.;

run;

proc score data $=$ SNPdata out $=$ ClusData score $=$ Makescore;

var SNP1 SNP2 SNP3 SNP4 SNP5 SNP6 SNP7 SNP8 SNP9 SNP10;

run;

proc genmod data = ClusData;

model Trait = Clus1 Clus2 Clus3;

run;

\section{References}

$\checkmark 1$ Heidema AG, Boer JMA, Nagelkerke N, Mariman ECM, Van Der A DL, Feskens EJM: The challenge for genetic epidemiologists: how to analyze large numbers of SNPs in relation to complex diseases. BMC Genet 2006; $7: 23$.

-2 Vermeulen SHHM, Den Heijer M, Sham P, Knight J: Application of multi-locus analytical methods to identify interacting loci in case-control studies. Ann Hum Genet 2007; 71:689-700.

3 Gauderman WJ, Murcray C, Gilliland F, Conti D: Testing association between disease and multiple SNPs in a candidate gene. Genet Epidemiol 2007;31:383-395.
-4 Wang K, Abbott D: A principal components regression approach to multilocus genetic association studies. Genet Epidemiol 2008; 32:108-118.

5 Jolliffe IT: Principal Component Analysis. New York, Springer, 2002.

6 Valle T, Tuomilehto J, Bergman RN, Ghosh S, Hauser ER, Eriksson J, Nylund S, Kohtamaki K, Tuomilehto-Wolf E, Toivanen L, Vidgren G, Ehnholm C, Blaschak J, Langefeld CD, Watanabe RM, Magnuson V, Ally DS, Hagopian WA, Ross E, Buchanan TA, Collins F, Boehnke M: Mapping genes for non-insulin dependent diabetes mellitus: design of the Finland-United States Investi- gation of NIDDM Genetics (FUSION) Study. Diabetes Care 1998;21:949-958.

7 Silander K, Mohlke KL, Scott LJ, Peck EC, Hollstein P, Skol AD, Jackson AU, Deloukas P, Hunt S, Stavrides G, Chines PS, Erdos MR, Narisu N, Conneely KN, Li C, Fingerlin TE, Dhanjal SK, Valle TT, Bergman RN, Tuomilehto J, Watanabe RM, Boehnke M, Collins FS: Genetic variation near the hepatocyte nuclear factor-4a gene predicts susceptibility to type 2 diabetes. Diabetes 2004; 53:1141-1149.

-8 Harris CW, Kaiser HF: Oblique factor analytic solutions by orthogonal transformations. Psychometrika 1964;29:347-362. 
-9 Damcott CM, Pollin TI, Reinhart LJ, Ott SH, Shen H, Silver KD, Mitchell BD, Shuldiner AR: Polymorphisms in the transcription factor 7-like 2 (TCF7L2) gene are associated with type 2 diabetes in the Amish: replication and evidence for a role in both insulin secretion and insulin resistance. Diabetes 2006;55:2654-2659.

10 Grant SF, Thorleifsson G, Reynisdottir I, Benediktsson R, Manolescu A, Sainz J, Helgason A, Stefansson H, Emilsson V, Helgadottir A, Styrkarsdottir U, Magnusson KP, Walters GB, Palsdottir E, Jonsdottir T, Gudmundsdottir T, Gylfason A, Saemundsdottir J, Wilensky RL, Reilly MP, Rader DJ, Bagger Y, Christiansen C, Gudnason V, Sigurdsson G, Thorsteinsdottir U, Gulcher JR, Kong A, Stefansson K: Variant of transcription factor 7-like 2 (TCF7L2) gene confers risk of type 2 diabetes. Nature Genet 2006;38:320-323.

-11 Saxena R, Gianniny L, Burtt NP, Lyssenko V, Giuducci C, Sjögren M, Florez JC, Almgren P, Isomaa B, Orho-Melander M, Lindblad U, Daly MJ, Tuomi T, Hirschhorn JN, Ardlie KG, Groop LC, Altshuler D: Common single nucleotide polymorphisms in TCF7L2 are reproducibly associated with type 2 diabetes and reduce the insulin response to glucose in nondiabetic individuals. Diabetes 2006;55: 2890-2895.

12 Weedon MN, Frayling TM, Shields B, Knight B, Turner T, Metcalf BS, Voss L, Wilkin TJ, McCarthy A, Ben-Shlomo Y, Davey Smith G, Ring S, Jones R, Golding J, ALSPAC Study Team, Byberg L, Mann V, Axelsson T, Syvanen AC, Leon D, Hattersley AT: Genetic regulation of birth weight and fasting glucose by a common polymorphism in the islet cell promoter of the glucokinase gene. Diabetes 2005;54:576-581.

-13 Winckler W, Weedon MN, Graham RR, McCarroll SA, Purcell S, Almgren P, Tuomi T, Gaudet D, Bostrom KB, Walker M, Hitman G, Hattersley AT, McCarthy MI, Ardlie KG, Hirschhorn JN, Daly MJ, Frayling TM, Groop L, Altshuler D: Evaluation of common variants in the six known maturity onset diabetes of the young (MODY) genes for association with type 2 diabetes. Diabetes 2007;56:685-693.

14 Dupuis J, Langenberg C, Prokopenko I, Saxena R, Soranzo N, Jackson AU, Wheeler E, Glazer NL, Bouatia-Naji N, Gloyn AL, Lindgren CM, Mägi R, Morris AP, Randall J, Johnson T, Elliott P, Rybin D, Thorleifsson G, Steinthorsdottir V, Henneman P, Grallert H, Dehghan A, Hottenga JJ, Franklin CS, Na- varro P, Song K, Goel A, Perry JR, Egan JM, Lajunen T, Grarup N, Sparsø T, Doney A, Voight BF, Stringham HM, Li M, Kanoni S, Shrader P, Cavalcanti-Proença C, Kumari M, Qi L, Timpson NJ, Gieger C, Zabena C, Rocheleau G, Ingelsson E, An P, O'Connell J, Luan J, Elliott A, McCarroll SA, Payne F, Roccasecca RM, Pattou F, Sethupathy P, Ardlie K, Ariyurek Y, Balkau B, Barter P, Beilby JP, Ben-Shlomo Y, Benediktsson R, Bennett AJ, Bergmann S, Bochud M, Boerwinkle $\mathrm{E}$, Bonnefond A, Bonnycastle LL, Borch-Johnsen K, Böttcher Y, Brunner E, Bumpstead SJ, Charpentier G, Chen YD, Chines P, Clarke R, Coin LJ, Cooper MN, Cornelis M, Crawford G, Crisponi L, Day IN, de Geus EJ, Delplanque J, Dina C, Erdos MR, Fedson AC, Fischer-Rosinsky A, Forouhi NG, Fox CS, Frants R, Franzosi MG, Galan P, Goodarzi MO, Graessler J, Groves CJ, Grundy S, Gwilliam R, Gyllensten U, Hadjadj S, Hallmans G, Hammond N, Han X, Hartikainen AL, Hassanali N, Hayward C, Heath SC, Hercberg S, Herder C, Hicks AA, Hillman DR, Hingorani AD, Hofman A, Hui J, Hung J, Isomaa $\mathrm{B}$, Johnson PR, Jørgensen $\mathrm{T}$, Jula A, Kaakinen M, Kaprio J, Kesaniemi YA, Kivimaki M, Knight B, Koskinen S, Kovacs P, Kyvik KO, Lathrop GM, Lawlor DA, Le Bacquer O, Lecoeur C, Li Y, Lyssenko V, Mahley R, Mangino M, Manning AK, Martínez-Lar$\operatorname{rad}$ MT, McAteer JB, McCulloch LJ, McPherson R, Meisinger C, Melzer D, Meyre D, Mitchell BD, Morken MA, Mukherjee S, Naitza S, Narisu N, Neville MJ, Oostra BA, Orrù M, Pakyz R, Palmer CN, Paolisso G, Pattaro C, Pearson D, Peden JF, Pedersen NL, Perola M, Pfeiffer AF, Pichler I, Polasek O, Posthuma D, Potter SC, Pouta A, Province MA, Psaty BM, Rathmann W, Rayner NW, Rice K, Ripatti S, Rivadeneira F, Roden M, Rolandsson O, Sandbaek A, Sandhu M, Sanna S, Sayer AA, Scheet P, Scott LJ, Seedorf U, Sharp SJ, Shields B, Sigurethsson G, Sijbrands EJ, Silveira A, Simpson L, Singleton A, Smith NL, Sovio U, Swift A, Syddall $\mathrm{H}$, Syvänen AC, Tanaka T, Thorand B, Tichet J, Tönjes A, Tuomi T, Uitterlinden AG, van Dijk KW, van Hoek M, Varma D, Visvikis-Siest S, Vitart V, Vogelzangs N, Waeber G, Wagner PJ, Walley A, Walters GB, Ward KL, Watkins $\mathrm{H}$, Weedon MN, Wild SH, Willemsen G, Witteman JC, Yarnell JW, Zeggini E, Zelenika D, Zethelius B, Zhai G, Zhao JH, Zillikens MC, DIAGRAM Consortium, GIANT Consortium, Global BPgen Consortium, Borecki IB,

Loos RJ, Meneton P, Magnusson PK, Nathan
DM, Williams GH, Hattersley AT, Silander K, Salomaa V, Smith GD, Bornstein SR, Schwarz P, Spranger J, Karpe F, Shuldiner AR, Cooper C, Dedoussis GV, Serrano-Ríos $\mathrm{M}$, Morris AD, Lind L, Palmer LJ, Hu FB, Franks PW, Ebrahim S, Marmot M, Kao WH, Pankow JS, Sampson MJ, Kuusisto J, Laakso M, Hansen T, Pedersen O, Pramstaller PP, Wichmann HE, Illig T, Rudan I, Wright AF, Stumvoll M, Campbell H, Wilson JF, Anders Hamsten on behalf of Procardis Consortium, MAGIC investigators, Bergman RN, Buchanan TA, Collins FS, Mohlke KL, Tuomilehto J, Valle TT, Altshuler D, Rotter JI, Siscovick DS, Penninx BW, Boomsma DI, Deloukas P, Spector TD, Frayling TM, Ferrucci L, Kong A, Thorsteinsdottir U, Stefansson K, van Duijn CM, Aulchenko YS, Cao A, Scuteri A, Schlessinger D, Uda M, Ruokonen A, Jarvelin MR, Waterworth DM, Vollenweider P, Peltonen L, Mooser V, Abecasis GR, Wareham NJ, Sladek R, Froguel P, Watanabe RM, Meigs JB, Groop L, Boehnke M, McCarthy MI, Florez JC, Barroso I: New genetic loci implicated in fasting glucose homeostasis and their impact on type 2 diabetes risk. Nature Genet 2010;42:105-116.

15 The International HapMap Consortium: The International HapMap Project. Nature 2003;426:789-796.

16 de Bakker PIW, Yelensky R, Pe'er I, Gabriel SB, Daly MJ, Altshuler D: Efficiency and power in genetic association studies. Nature Genet 2005;37:1217-1223.

17 Barrett JC, Fry B, Maller J, Daly MJ: Haploview: analysis and visualization of $\mathrm{LD}$ and haplotype maps. Bioinformatics 2005;21: 263-265.

18 Love-Gregory LD, Wasson J, Ma J, Jin CH, Glaser B, Suarez BK, Permutt MA: A common polymorphism in the upstream promoter region of the hepatocyte nuclear factor- $4 \alpha$ gene on chromosome $20 \mathrm{q}$ is associated with type 2 diabetes and appears to contribute to the evidence for linkage in an Ashenazi Jewish population. Diabetes 2004; 53:1134-1140.

19 Zou H, Hastie T, Tibshirani R: Sparse principal components analysis. J Comput Graph Stat 2006; 15:265-286.

20 Kleinjan DA, van Heyningen V: Long-range control of gene expression: emerging mechanisms and disruption in disease. Am J Hum Genet 2005;76:8-32.

21 West AG, Fraser P. Remote control of gene transcription. Hum Mol Genet 2005; 14:R101-R111. 